This item was submitted to Loughborough's Research Repository by the author.

Items in Figshare are protected by copyright, with all rights reserved, unless otherwise indicated.

\title{
Ethics in action: consent-gaining interactions and implications for research
} practice

\section{PLEASE CITE THE PUBLISHED VERSION}

http://dx.doi.org/10.1111/bjso.12009

PUBLISHER

Wiley (C) The British Psychological Society

VERSION

AM (Accepted Manuscript)

LICENCE

CC BY-NC-ND 4.0

\section{REPOSITORY RECORD}

Speer, Susan A., and Elizabeth Stokoe. 2019. "Ethics in Action: Consent-gaining Interactions and Implications for Research Practice". figshare. https://hdl.handle.net/2134/13261. 
This item was submitted to Loughborough's Institutional Repository (https://dspace.lboro.ac.uk/) by the author and is made available under the following Creative Commons Licence conditions.

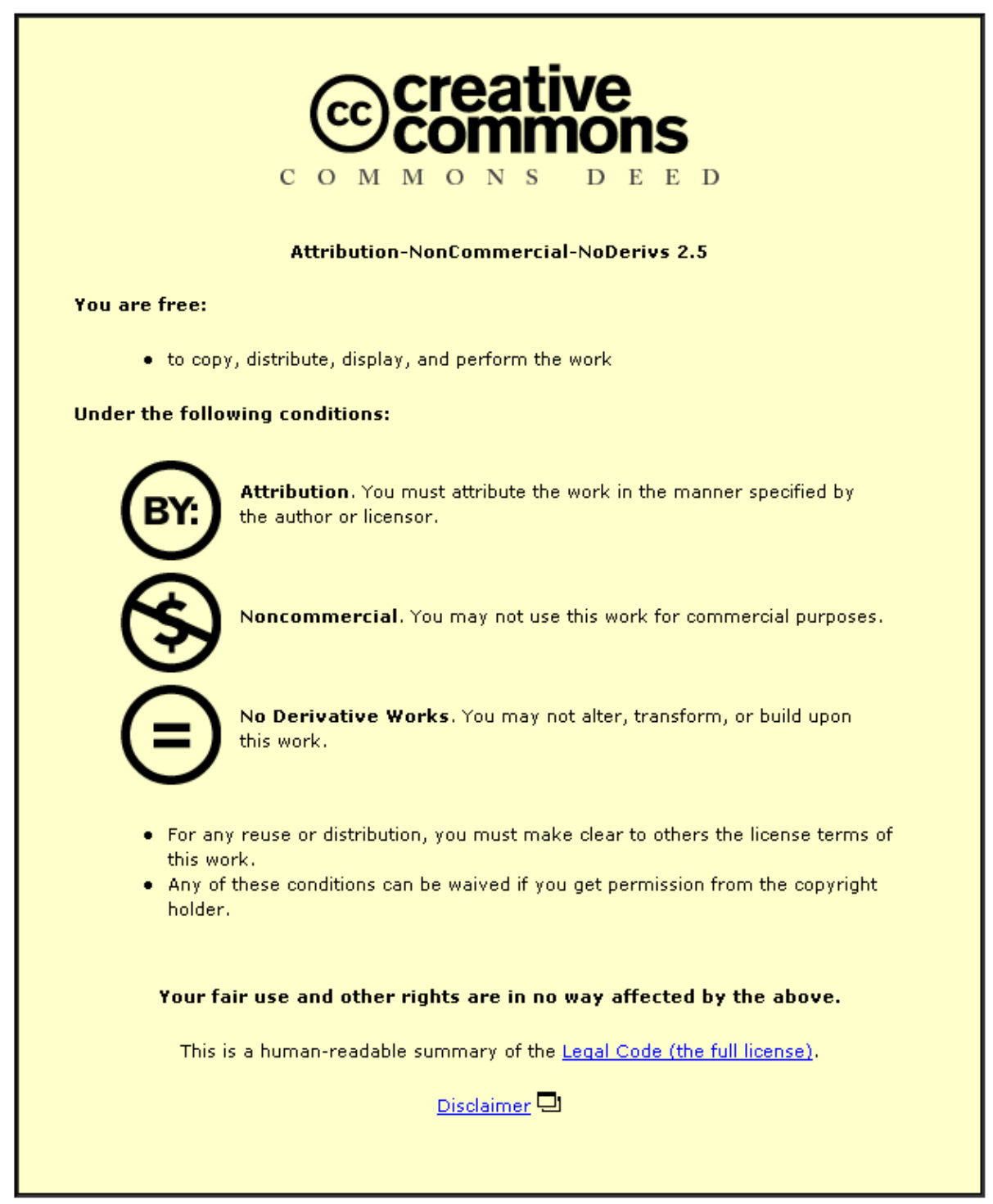

For the full text of this licence, please go to: http://creativecommons.org/licenses/by-nc-nd/2.5/ 


\section{Ethics in action: Consent-gaining interactions and implications for research practice}

\section{Susan A. Speer* and Elizabeth Stokoe}

Dr Susan A. Speer

Senior Lecturer in Psychology

School of Psychological Sciences (Psychology Division)

Coupland Building 1

The University of Manchester

Oxford Road

Manchester M13 9PL

UK

Email: susan.speer@manchester.ac.uk

Professor Elizabeth Stokoe

Department of Social Sciences

Loughborough University

Loughborough

Leicestershire

LE11 3TU

UK

Email: e.h.stokoe@lboro.ac.uk

*Requests for reprints should be addressed to: Dr Susan A. Speer

Senior Lecturer in Psychology, School of Psychological Sciences (Psychology Division), Coupland Building 1, The University of Manchester, Oxford Road, Manchester M13 9PL

UK. Email: susan.speer@manchester.ac.uk

Word count (exc. Abstract/figures/tables/reference list and title pages): 8021 


\section{Acknowledgements}

An earlier version of this article was written and presented by the first author as a keynote presentation at the conference "'Would you mind if I record this?" Ethics and methodology in discourse interaction research", New University of Lisbon, Lisbon, Portugal, August 2011. The authors gratefully acknowledge the support of the UK Economic and Social Research Council Identities and Social Action Programme, Award numbers RES-148-25-002 and RES148-25-0010. 


\begin{abstract}
This paper deals with the topic of social psychological research methods in practice, by examining how informed consent is gained from research participants. In most research, the consent-gaining process is hidden from analytic scrutiny and is dealt with before data collection has begun. In contrast, conversation analytic research, which records interactional encounters from beginning to end, enables examination of this methodological 'black box'. We explored how 'requests' to consent in research played out across different institutional settings. We found that participants had to 'opt-out' of a research process that was already underway. Consent-gaining sequences constrained opting out in two ways: (1) because research activity was already underway, it must be stopped affirmatively by participants; (2) consent-gaining turns were tilted in favour of continued participation, making opting-out a dispreferred response. We also found a mismatch between what ethics guidelines specify about consent-gaining 'in theory' and what actually happens 'in practice'. Finally, we make suggestions about interventions in and recommendations for existing practice to best achieve informed consent.
\end{abstract}

[166 words]

Keywords: Ethics, interaction, informed consent, conversation analysis, requests 


\section{INTRODUCTION}

This paper addresses social psychological research methods in practice. More specifically, it examines the way that informed consent is gained from research participants in studies of social interaction. Under the heading of "standards of informed consent", the British Psychological Society's (2009) Code of Ethics and Conduct lists several principles which are shared by professional bodies across a range of disciplines (e.g., American Psychological Association, 2010; National Institutes of Health, 2004). The code states that "psychologists should ensure that clients, particularly children and vulnerable adults, are given ample opportunity to understand the nature, purpose, and anticipated consequences of any professional services or research participation, so that they may give informed consent to the extent that their capabilities allow" (2009: 12). However, the code gives no advice about communicating issues of consent or what 'informed' consent should look like in practice. The General Medical Council (GMC), the UK body which regulates doctors, is similarly prescriptive without supplying a script, stating that valid consent occurs when participants agree "to participate without pressure or coercion" (GMC, 2010: 8), have been given "the information they want or need in order to decide whether to take part in research" (ibid., p. 8), and should be "encourage[d] ... to ask questions" (GMC 2008: 10).

Many studies, particularly in medicine, have sought to improve informed consent processes by examining patients' understanding of research protocols and different methods for obtaining consent (e.g., Dunn \& Jeste, 2001; Eyler \& Jeste, 2006; Flory \& Emanuel, 2004; Penn \& Evans, 2009; Woodsong \& Karim, 2005). However, given the importance of informed consent to professional bodies, ethics committees and institutional review boards, it is surprising that in most research practice, including in social psychology, the consentgaining process is largely hidden from analytic scrutiny. Instead, matters of consent are either glossed in short sentences (e.g., "Before completing the questionnaires, participants read, and 
signed informed consent sheets": Livingstone, Manstead, Spears \& Bowen, 2011) or are absent entirely (e.g., Tanis \& Beukeboom, 2011). Of course, the fact that consent must be obtained from participants "before involving them in any research project" (GMC, 2010: 4, emphasis added) means that data to investigate consent-gaining interactions is limited. However, conversation analytic and discursive psychological studies of social interaction are perhaps uniquely placed to interrogate such interactions. This is because, unlike in experimental and (much of) qualitative social psychology matters of consent are dealt with inside the research process itself, within research recordings, as an endogenous feature of them. Thus, consent-gaining is handled spontaneously, in the live unfolding of talk.

A handful of studies use conversation analysis (CA) to examine consent-gaining interactions. Toerien and Donovan (2007) and Wade, Donovan, Lane, et al (2009) analyzed clinical trial recruitment appointments, and found that "informed consent" and "systematic exploration of each participant's concerns" could be facilitated by "strategic use of open questions, pauses and ceding the floor in the interaction" (Wade et al, 2009: 2018). Application of these strategies helped to "protect participants against coercion" and made "leading questions less likely" (ibid.: 2026). While Wade and colleagues examined participants consenting to future medical trials, how they consent in concurrent research activities remains unknown, with two notable exceptions: Maynard and colleagues (e.g., Maynard \& Schaeffer, 2002; Maynard, Freese \& Schaeffer, 2010) examined recruitment requests in telephone survey 'cold-calls' to prospective participants, while Mondada (2006a, 2011) examined the way participants negotiate various ethical concerns (e.g., requesting and resisting participation, anonymization, orienting to the recording device) during recorded research activities.

The current paper extends this work by exploring how consent-gaining interactions unfold in recordings made for social psychological research purposes across a range of 
institutional settings. In so doing, it also contributes to ethnomethodologically-based studies of research methods in practice (e.g., Drew, Raymond \& Weinberg, 2006; Gibson, 2011; Maynard et al., 2002; Mondada 2006b; Speer, 2002a, 2002b, 2002c; Speer \& Hutchby, 2003a, 2003b). In this work, rather than treating research methods as a resource to obtain data, they are treated as a topic for analysis in their own right. For example, turning the methodological problem of 'reactivity' on its head, Speer and Hutchby (2003a, 2003b; Hammersley, 2003) explored participants' orientations to the presence of recording devices, showing how 'tape-affected speech' does not necessarily render overtly-recorded (ethical) data 'unnatural' (Speer 2002a, 2002b; see also Stokoe, 2009). Such studies have transformed our understanding of research processes by highlighting the contrast between research methods 'in theory', as set out in textbooks and research protocols, and research methods 'in practice' (cf. Gilbert \& Mulkay, 1984). As we will show, such matters are relevant to consent-gaining interactions.

The paper has two aims. First, we take the methodological 'black box' of informed consent as our topic and explore what consent-gaining sequences look like in practice. We examine the grammatical design of consent-requests, the sequential environments in which they occur, and the responses they occasion. Second, we explore the contrasts between consent-gaining interaction 'in theory' and the actual production of such interaction 'in practice'. We reflect on the questions our analyses raise for informed consent and the ethics of social psychological research practice.

\section{DATA AND METHOD}

The paper draws on datasets collected for three different social psychological research projects: 
(1) 156 audio-recordings and 38 video-recordings of psychiatrist-patient consultations in a National Health Service (NHS) Gender Identity Clinic, and 21 recorded telephone research interviews between Speer and transsexual patients who attended the GIC, were collected by Speer for an ESRC-funded study of the construction of gender identities. Ethical approval was granted by the NHS Central Office of Research Ethics Committees. Participants received participant information sheets and consent forms (see Figure 1) prior to their consultation. All participants were given the opportunity to ask questions about the study at their appointment with the psychiatrist, where, if they consented, they also signed the consent forms.

(2) Approximately 500 audio recordings of telephone calls between members of the public and UK neighbour mediation services, local council environmental health and antisocial behaviour services were collected as part of Stokoe's ESRC-funded study of neighbour disputes. Consent was gained via the call-taker (a mediator or council officer) formulating an 'ethics script' that was negotiated with the researcher. As is common practice in studies of professional-client interaction, information about the project and informed consent was supplied, but the actual wording was left to the professional to manage. A University ethics form was completed and approved.

(3) Finally, we drew on a corpus still under collection by Stokoe, of routine calls to organizations (e.g., electricity companies, local councils, banks, local doctors) which use prerecorded messages to inform callers that their call will be recorded. Incoming calls are answered with a recorded message or menu of options, before speaking to a human call-taker. As above, a University ethics form was completed and consent gained during the call.

Using data from a range of institutional settings increases the generalizability of our findings, showing both systematic, setting-specific variations in the interactional practices of 
consent-gaining that we identify, as well as their generic or 'context free' features (Speer, in press). Across all datasets, the recording party varied when in the overall interaction they initiated consent-gaining sequences, having their own preferred design and account for its placement. For example, some GIC doctors conducted the majority of form-filling and consent-gaining off-tape, or part off-tape and part on-tape. Others completed the entire process at the start or the end of assessment sessions. Likewise, some mediators asked callers for their consent at the end, rather than at the start, of the telephone calls. We will consider the implications of these differences as we move through the analysis.

All data were transcribed using Jefferson's (2004) conventions for conversation analysis, and identifying features were changed. Consent-gaining sequences were analyzed using CA to identify recurrent interactional practices, focusing particularly on turn design, grammar and action formation (how are matters of consent formulated, into what sorts of turns?), and the sequential organization of the pairs of turns through which the actions of interest were accomplished (where are matters of consent located in the ongoing interaction?).

\footnotetext{
ANALYSIS

In Section (1), we deal with a pervasive and mundane form of recording that occurs in most people's daily lives: the pre-recorded message in calls to organizations who record without consent. We consider the implications of such practices for the analysis of consent-gaining sequences in research encounters. Sections (2) and (3) explicate the most common methods, in our different datasets, through which consent was gained. We examine the similarities and differences in the way recording parties announce that the interaction is being recorded, and how such announcements are treated by recipients as a request to record. In Section (4), we consider an extended sequence of face-to-face consent-gaining from a medical setting,
} 
exploring what happens when a formal consent form is verbalized by the doctor. Across the analysis, we investigate the different states of affairs that are formulated in consent-gaining sequences, which attend to matters of 'entitlement' to make the request, the 'contingency' associated with granting it (see Curl \& Drew, 2008), and the possibilities for opting in or out of the recording process.

\section{(1) The pre-recorded message: Announcing (and resisting) recording without seeking}

\section{consent}

Issues of consent to record enter everyday life in the pre-recorded messages that people hear when they call public and private organizations and businesses, before they receive a menu of options to choose from, or before speaking to an employee. Consider Extracts 1 and 2, below. ' $R M$ ' is the voice of the pre-recorded message.
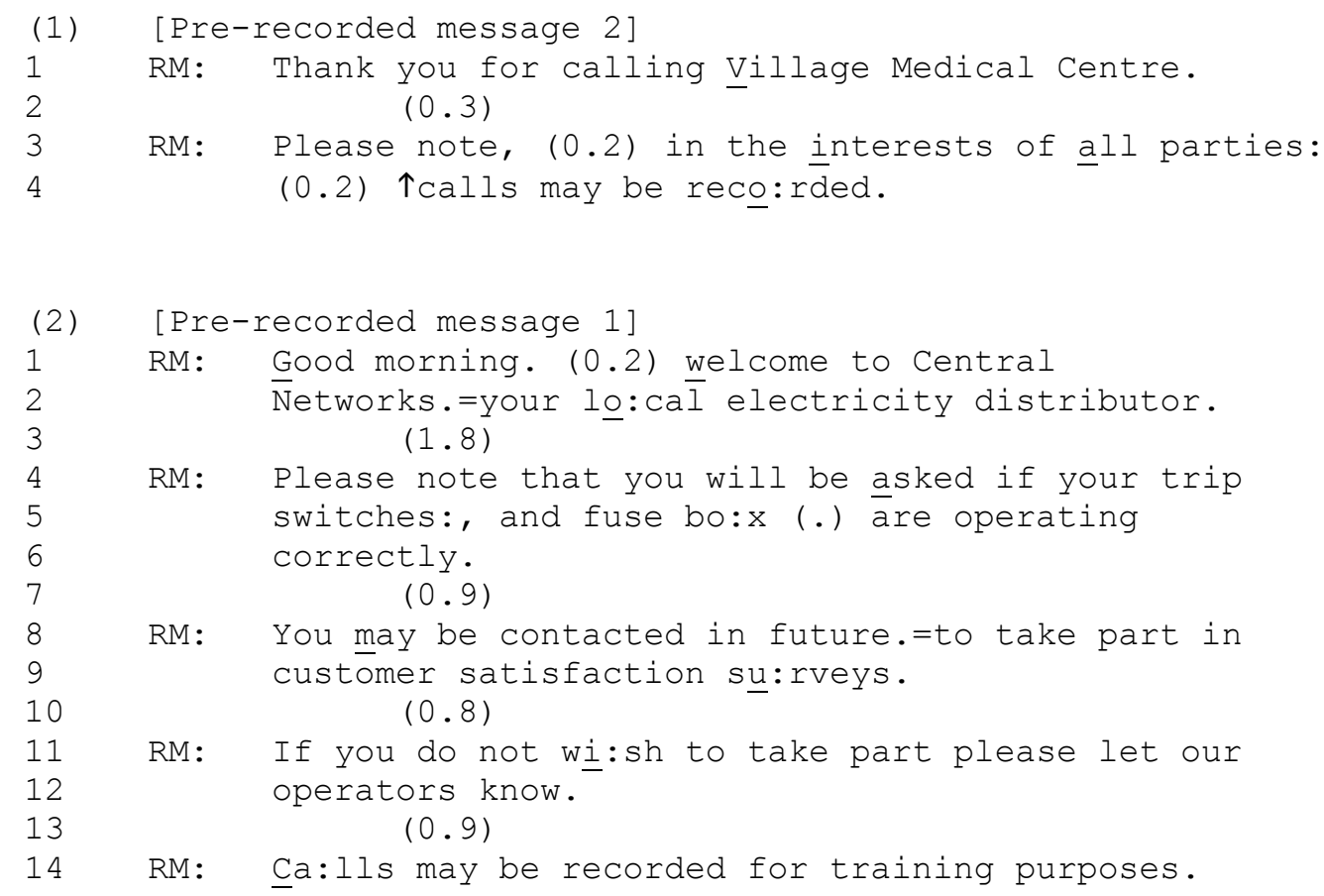

The pre-recorded message informs recipients that their calls "may be recorded", via a declarative announcement (Terasaki, 2004). An account is also supplied: "in the interests of 
all parties:" (Extract 1), or "for training purposes" (Extract 2). In Extract 2, callers are also forewarned that they "may be contacted in future.=to take part in customer satisfaction su:rveys." (lines 8-9), and are asked to "let our operators know" if they "do not wị:sh to take part" in that future study (lines 11-12). Here, then, are two routine practices relevant to informed consent: announcing that the current call is being recorded without seeking permission, and assuming that the caller consents to participate in further research at some unspecified future date unless they explicitly 'opt out' during the call. Recipients cannot refuse the action that is initiated by the announcement (the recording of the call): there is no 'slot' for a response. In this sense, these are not consent-gaining 'interactions' at all; consent occurs by default rather than achievement.

Extract 3 is an example of a Garfinkel-inspired 'breaching experiment'. As Garfinkel (1967) has shown, it is often only in breaches of a normative pattern that the strength of that norm becomes visible. Indeed, we suggest that the pervasiveness of recording without consent is evidenced by the interactional difficulties a caller has when attempting to withhold their consent.

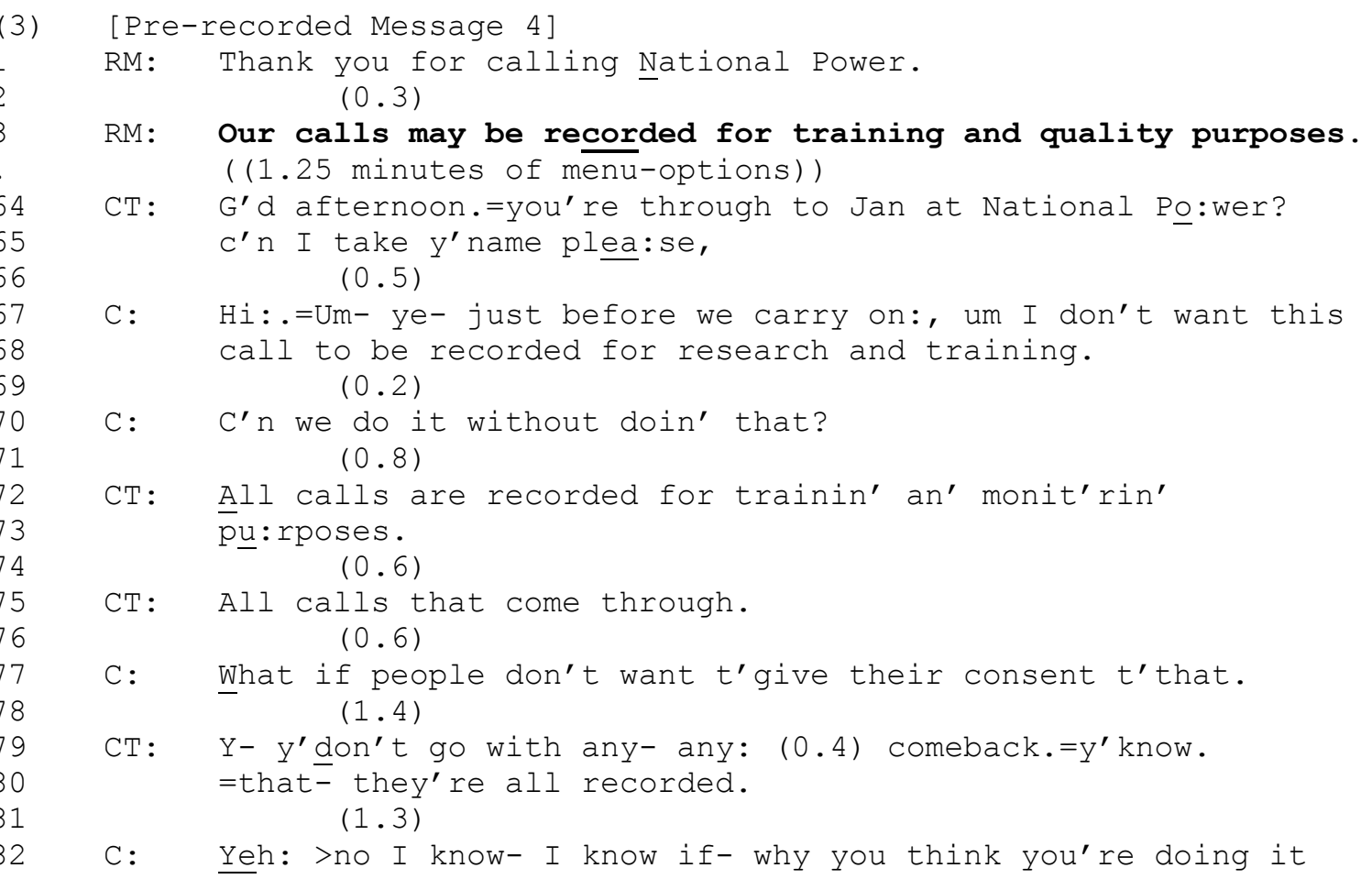




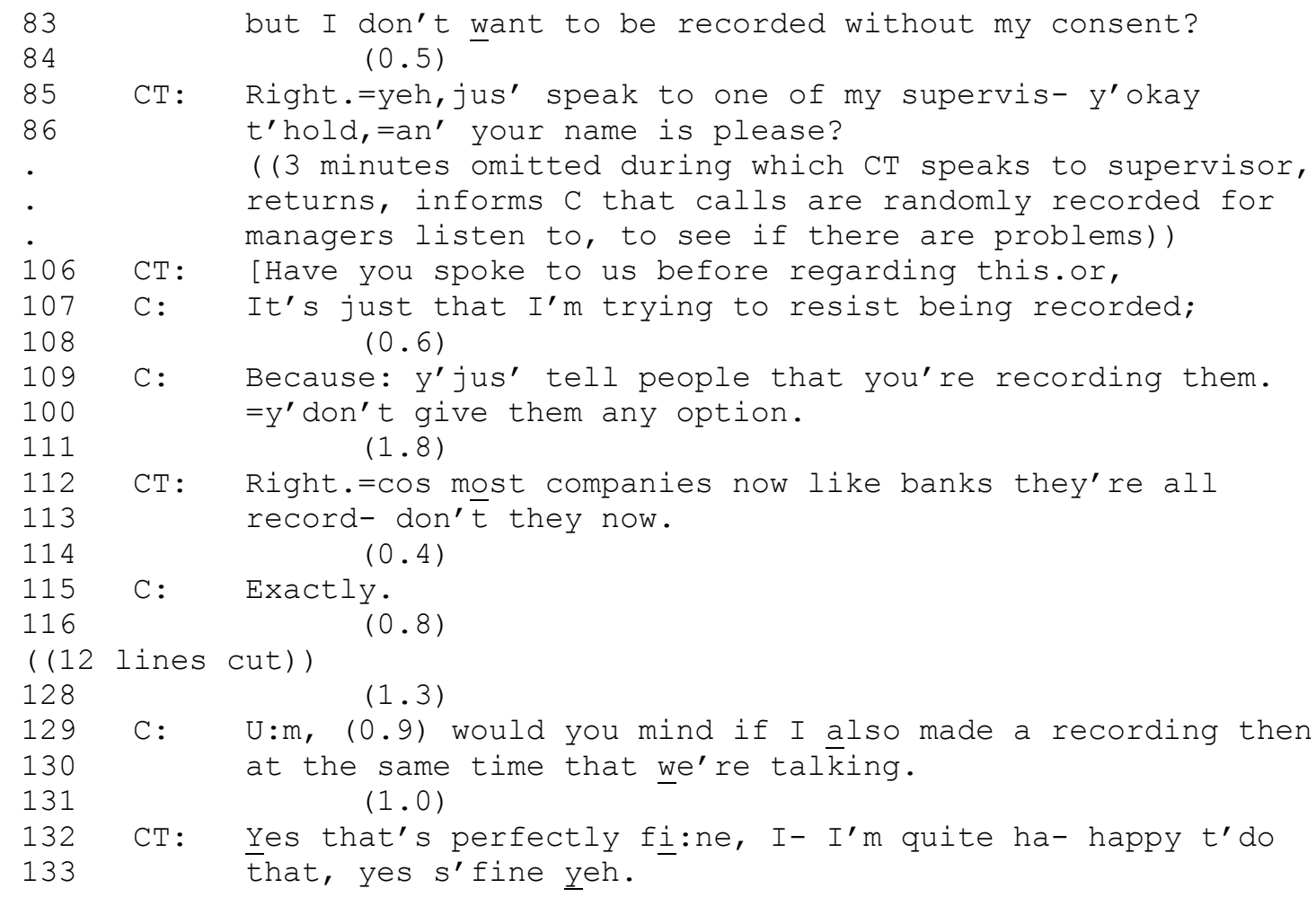

The caller attempts to withhold her consent by announcing that she does not want the call to be recorded (lines 67-70), before explicitly requesting that it is not recorded (line 70). As conversation analysts have shown, the interactionally preferred response to a request - one which furthers the course of action initiated by it - is a granting (Schegloff, 2007). However, the call-taker's response is 'dispreferred': it declines the request by supplying the account given in the pre-recorded message, reiterating the company policy (line 72). Declining consent is not, in fact, an option. When the caller pursues the issue (lines 77, 82-3), the calltaker puts her on hold to confer with supervisors (lines 86ff), before accounting for her organization's practice (and her dispreferred response), by asserting that "most companies now like banks they're all record- don't they now" (lines 112-13). Notice how “don't they now" pursues the caller's agreement as if it were a matter of common knowledge (Hepburn \& Potter, 2011). In other words, instead of treating recording without consent as an accountable matter, the call-taker invokes as a cultural norm the notion that people are routinely recorded when interacting with organizations on the telephone. Finally, the caller seeks the call-taker's 
consent to make a concurrent recording using the low entitlement, high contingency request form ("would you mind if..." at lines 129-30; cf. Curl \& Drew, 2008; see also Heinemann, 2006; Lindström, 2005). Unlike the announcement in the recorded message, this request makes relevant either a granting or declining (the call-taker grants the request: lines 132-33). As we will go on to show, one striking feature of the consent-gaining turns in our corpus is that they are rarely formulated in this way, as low entitlement, high contingency 'requests'.

In Extracts 1-2, then, in which the call may or may not be recorded for 'training' purposes, we see a high entitlement declaration about recording, with no slot for response and, as Extract 3 demonstrates, the near-impossibility of opting-out. Our examples establish the normative nature of recording without consent. As we will see, the fact that people are so used to this practice has implications for the ways that consent-gaining occurs in research settings.

\section{(2) Announcing the interaction is being recorded}

In Section (1), the embedding of a recording announcement in a pre-recorded message precluded recipients from responding by failing to provide a slot for any next turn. In Section (2), we examine extracts in which recording parties seek consent from recipients. Extracts 4-6 come from calls to or from different mediation and environmental health services.

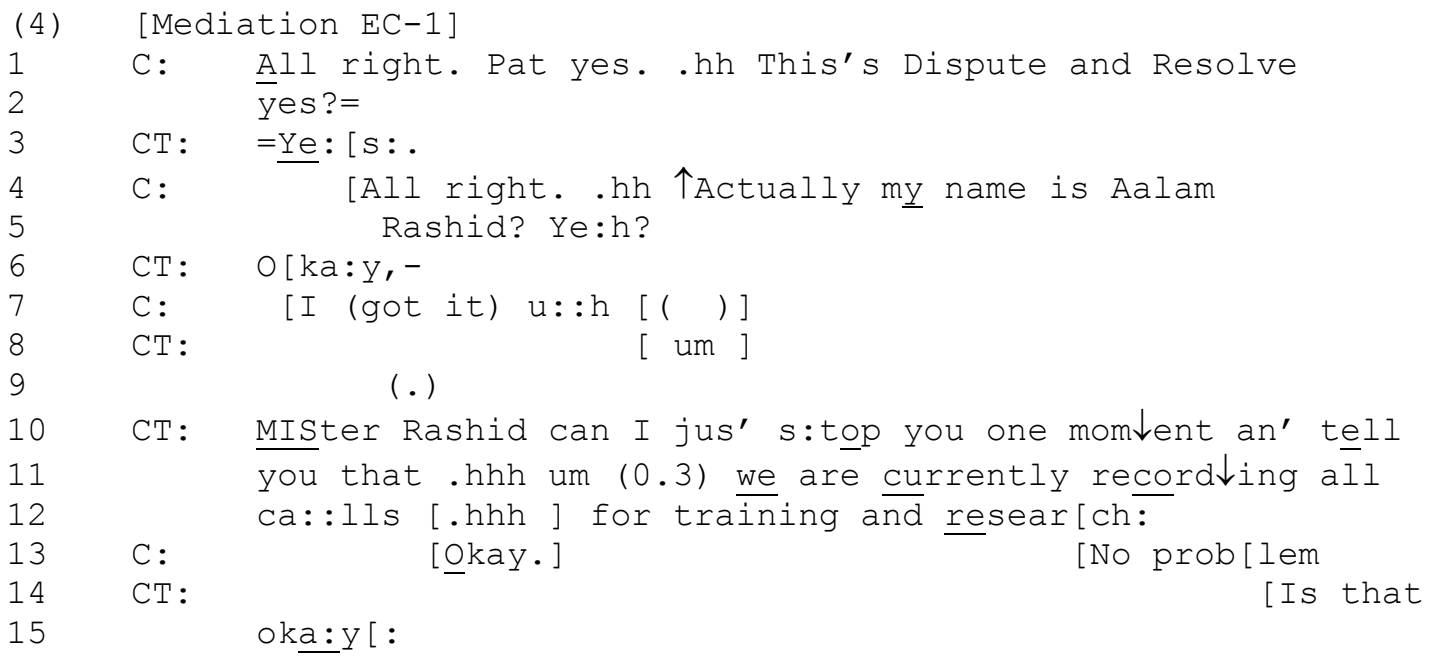




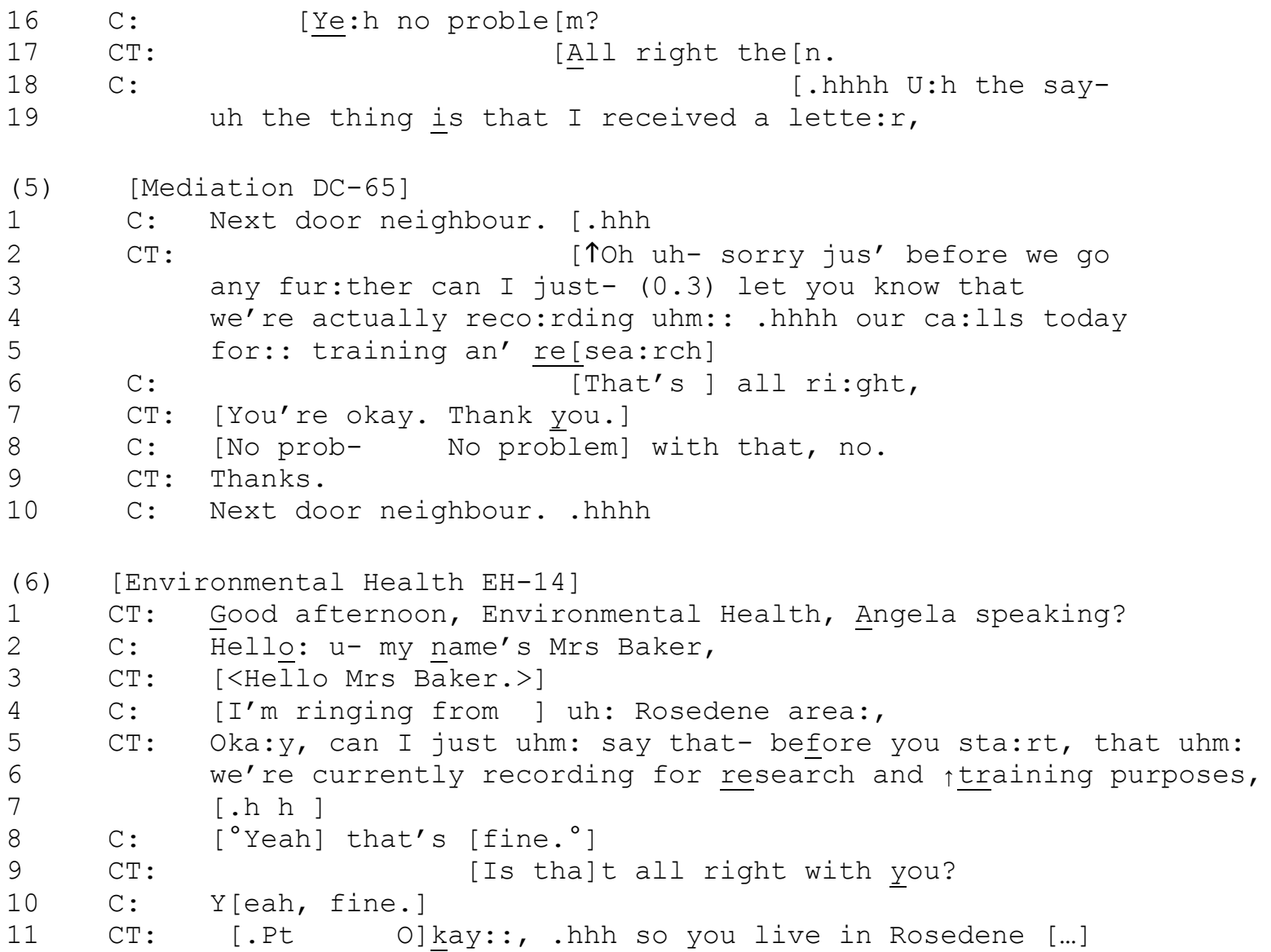

Four components comprise these consent-gaining sequences:

(i) The recording-party announces that the interaction is being recorded.

After initial greetings and/or the start of C's problem formulation, the call-taker disrupts the progressivity of the call to launch the consent-gaining sequence ("can I jus' s:top you one

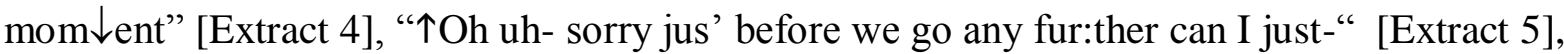
"can I just uhm: say that- before you sta:rt" [Extract 6]), minimizing the disruption with the word "just" and, in the case of Extract 5, apologizing for the interruption. Consent-gaining sequences were launched as soon as possible after call openings, before callers disclosed their problem and any personal information. Intuitively, one might expect that in recordings made for research purposes, the consent-gaining turn would be formatted as a grammatical 'request' with low entitlement - much like the caller's request in Extract 3 ("would you mind 
if...”). However, such formulations were absent from our datasets. Rather, consent-gaining turns were formulated by the recording-party in a similar fashion to the pre-recorded message, as a declarative announcement, and fait accomplis ("tell you" [Extract 4] "let you know" [Extract 5], "say that-" [Extract 6]), with similar 'training-and-research'-based accounts, in a manner that assumes consent to the ongoing recording will be "noncontingent" (Curl \& Drew, 2008: 147).

However, note that call-takers' turns nevertheless contain some markers of hesitation, and that recordings are presented as something the organization is doing 'today' rather than routinely. These features introduce a degree of cautiousness into the consent-gaining process. Furthermore, the topic is launched with conventional indirectness (e.g., "Can I just let you know...": see Brown \& Levinson, 1987) which may communicate a reduced level of imposition on the caller and the overall entitlement of the organization to record the calls.

(ii) Recipients treat announcements as a request to record, and give their consent.

Schegloff notes that "some types of first pair parts" (e.g., announcements, noticings and tellings) "can function doubly, both as actions in their own right and as vehicles ... for other actions" (2007: 73). Thus, although the consent-gaining turns are built grammatically as announcements, the recipients do not treat them as such (e.g., with "oh!" - assessing the "news" that they are being recorded, see Terasaki, 2004). Rather, they treat them as requests to record, and provide 'preferred', consenting responses that progress the course of action initiated by the announcement. Consenting responses come either slightly early in the course of the announcement, projecting the completion of the recording-parties' turn (Extracts 4 and 5), or upon its completion (Extract 6), indicating that it is "no problem" (Extract 4), "all ri:ght" (Extract 5) or "fine" (Extract 6). 
(iii) Recording-parties check that consent is given

Once callers have given their consent, call-takers expand the sequence by adding a new turn component (and a second adjacency pair) formulated as an interrogative or declarative 'question' "They ask: "Is that oka:y:" (Extract 4), "You're okay” (Extract 5) and "Is that all right with you?" (Extract 6). Since they are built grammatically to prefer a 'yes' response (Heritage \& Raymond, frth; Raymond, 2003), these confirmation-seeking components are presumptive in their design, aligned to the on-going recording. However, coming after and expanding consent-gaining sequences that were initiated in an entitled way, they may function to mitigate that entitlement post-hoc. They may also be accounted for by the fact that the callers' consent is given partly in overlap. In Extracts (4) and (6), the confirmation check is begun in overlap with the caller's response, overlapping directly the word that conveys assent ("problem"; "fine"). In (5) where the assent word emerges 'in the clear', the call-taker pursues re-confirmation through a declarative question: "You're okay." (the method of choice for reconfirmation: see Stivers et al, 2009). Thanking the caller further indexes lower entitlement: the request was 'genuine'. The upshot of this is that these confirmation checks may be better construed as the point at which call-takers 'request permission' for the recording, and not merely reconfirmations of a prior affirmation.

\section{(iv) Recipients re-confirm their consent.}

Callers re-confirm their consent 'in the clear' by repeating some variation of their original consent-giving response (“Ye:h no problem?” [Extract 4]; "No problem” [Extract 5]; and "Yeah, fine" [Extract 6]. Upon receipt of this confirmation, call-takers close down the consent-gaining sequence "[ㅅll right then" [Extract 4], "Thanks" [Extract 5] and "O]kay::" [Extract 6], prompting callers to (re)start their problem formulation.

Extracts 4-6 show that consent-gaining 'requests' are, in fact, formulated in ways similar to the declarative announcements in pre-recorded messages, albeit that they are 
treated as requests to grant or deny and with lower entitlement. We might speculate that, because of the familiarity of pre-recorded messages, including their wording, call-takers find themselves using these as idiomatic formulations, which, as such, are projectable by recipients and treated as requests to record. The main differences between the extracts in this and the previous section are that, first, callers know that recording is definitely going forward (rather than it 'may' do). Second, callers may (although never do, in our corpora, outside of the 'breaching' calls) decline the embedded request. Third, announcements about recording are embedded in turns which are treated as requests, with various features that attend to matters of entitlement and contingency. Finally, recording-parties confirm that callers have given their consent, expanding the sequence and adding a further question component in their next turn.

\section{(3) Announcing that the interaction is being recorded and soliciting consent}

In different ways to Section (2), in Section (3) the recording party initiates consent-gaining sequences by announcing to the recipient that the interaction is being recorded but then, as part of their turn design, solicits explicitly their consent by incorporating or adding one or more incremental turn component(s) that (a) seeks confirmation that it is "okay" to record, and/or (b) offers grounds for declining consent, before consent is given. Extracts 7 and 8 come from a collection of telephone research interviews with transsexual patients who had attended a Gender Identity Clinic for assessment. In contrast to participants in the mediation and council data, patient-participants had already received participant information sheets informing them that their interview would be recorded, and signed consent forms. Therefore, in this context, requests to record reconfirm consent already given.

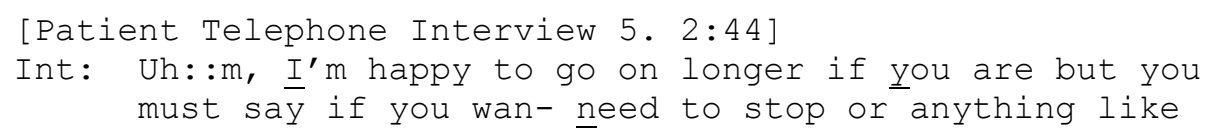




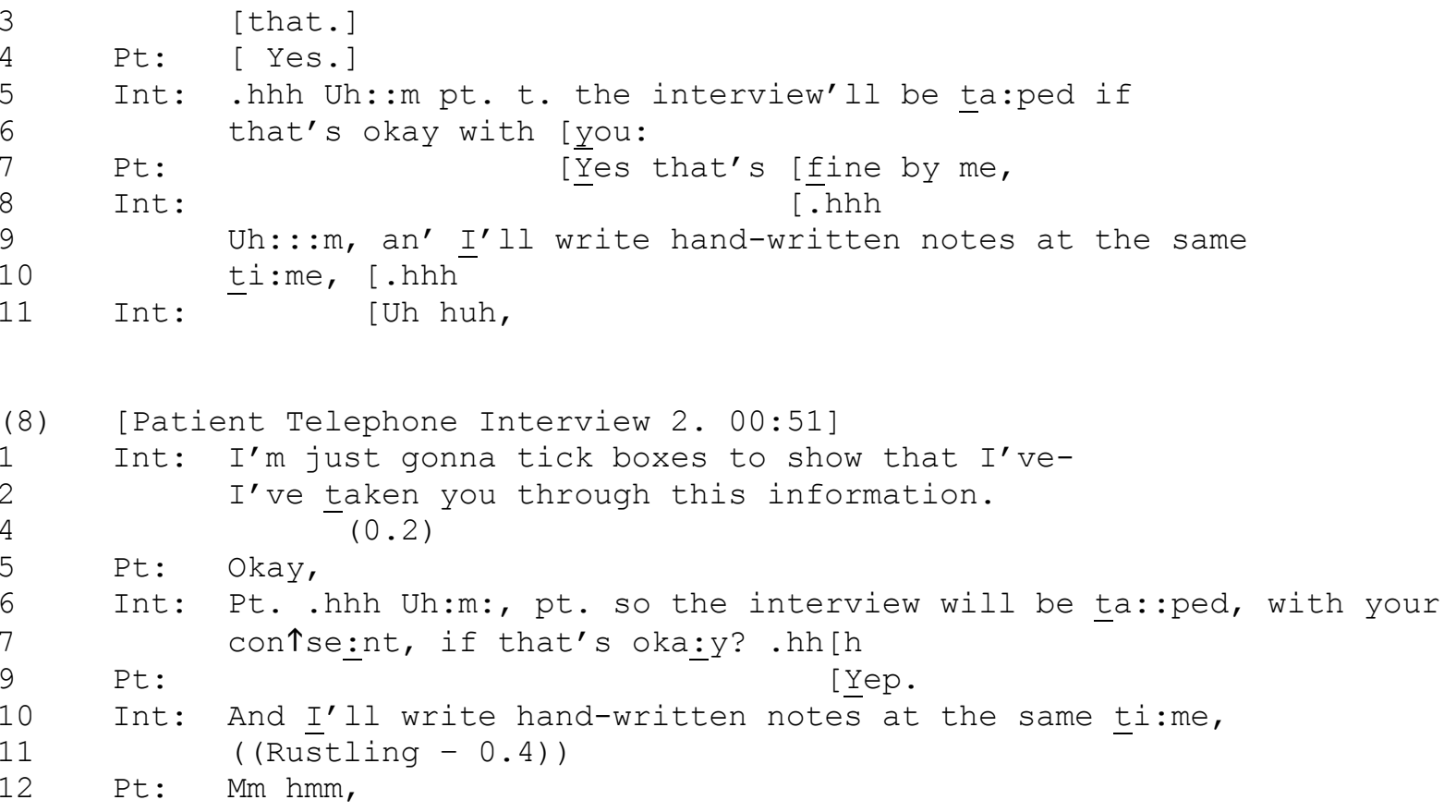

While the announcements in Extracts 4-6 were prefaced with modalized phrases such as "can I just", downgrading the entitlement of the organization to make the recordings, the announcements in Extracts 7 and 8 contain no such prefaces. Furthermore, unlike the sequence-expanding, consent-soliciting questions in Section 2, the consent-soliciting components in Extracts 7 and 8 do not form part of an expanded sequence but are tagged onto, or grammatically continuous with, the announcement. The recording party invites the recipient to confirm that it is "okay" to record (Extract 7, line 5-6; Extract 8, lines 6-7) before continuing delivering information about the study. The recipient subsequently gives their consent (Extract 7, line 7; Extract 8, line 9). In each case, a further understanding check is not initiated and the recording-party moves on to a next action. These two differences may be accounted for in part because the participants have already granted consent to participate in the study; these are 'informings' with higher institutional entitlement and lower contingency. While the opt-out orientation remains, participants have already signed consent forms. However, like the call-takers in Extracts 4-6, contingency is still oriented to in clauses such as "if that's okay with you" and "if that's oka:y?". 
An alternative method for soliciting consent is exemplified in Extract 9, from a call to an antisocial behaviour council officer:

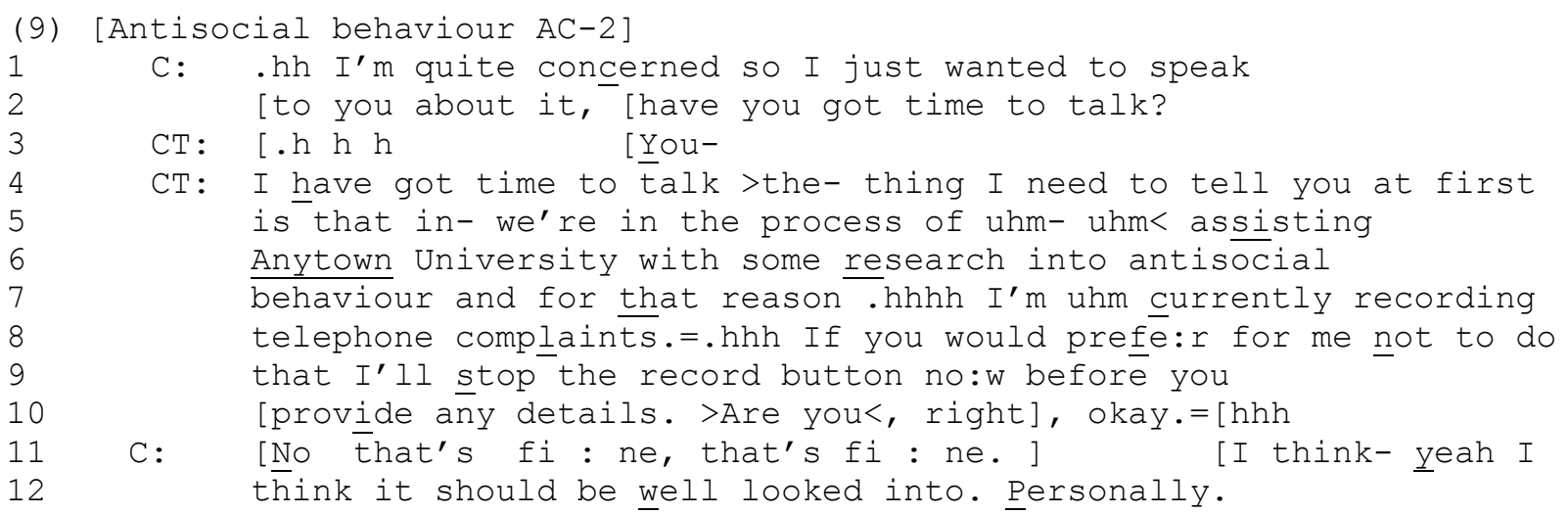

Like Extracts 7 and 8, the call-taker starts with an announcement about the recording, prefaced with an institutional account ("I need to tell you..." [line 4]). But, in anticipation of a dispreferred (non-consenting) response, they rush through the transition space (line $8-$ the in-breath indicates a continuation of the turn), adding a turn component that voices potential grounds for declining consent ("If you would prefe:r for me not to do that" [lines 8-9]) and which offers to stop the recording (lines 9-10). Extract 9, then, is an example in which the possibility of opting out (and the contingency associated with assenting) is articulated explicitly, orienting to a possible dispreferred response. However, the caller interrupts the call-taker's turn in order to explicitly reject the offer to stop recording, and assent to the original, implicit request to record the call ("No that's fi:ne, that's fi:ne." [line 11]). Extract 10 contains two similar practices, of adding one or more incremental turn component(s) that seek confirmation that it is "okay" to record, and offering grounds for declining consent, before consent is given.

(10) [Mediation helpline $\mathrm{HC}-17]$

1 C: I just saw the leaflet and thought [it might- help becau[se, $2 \mathrm{CT}: \quad[\mathrm{Mm}:, \quad[Y e:$ ah. 


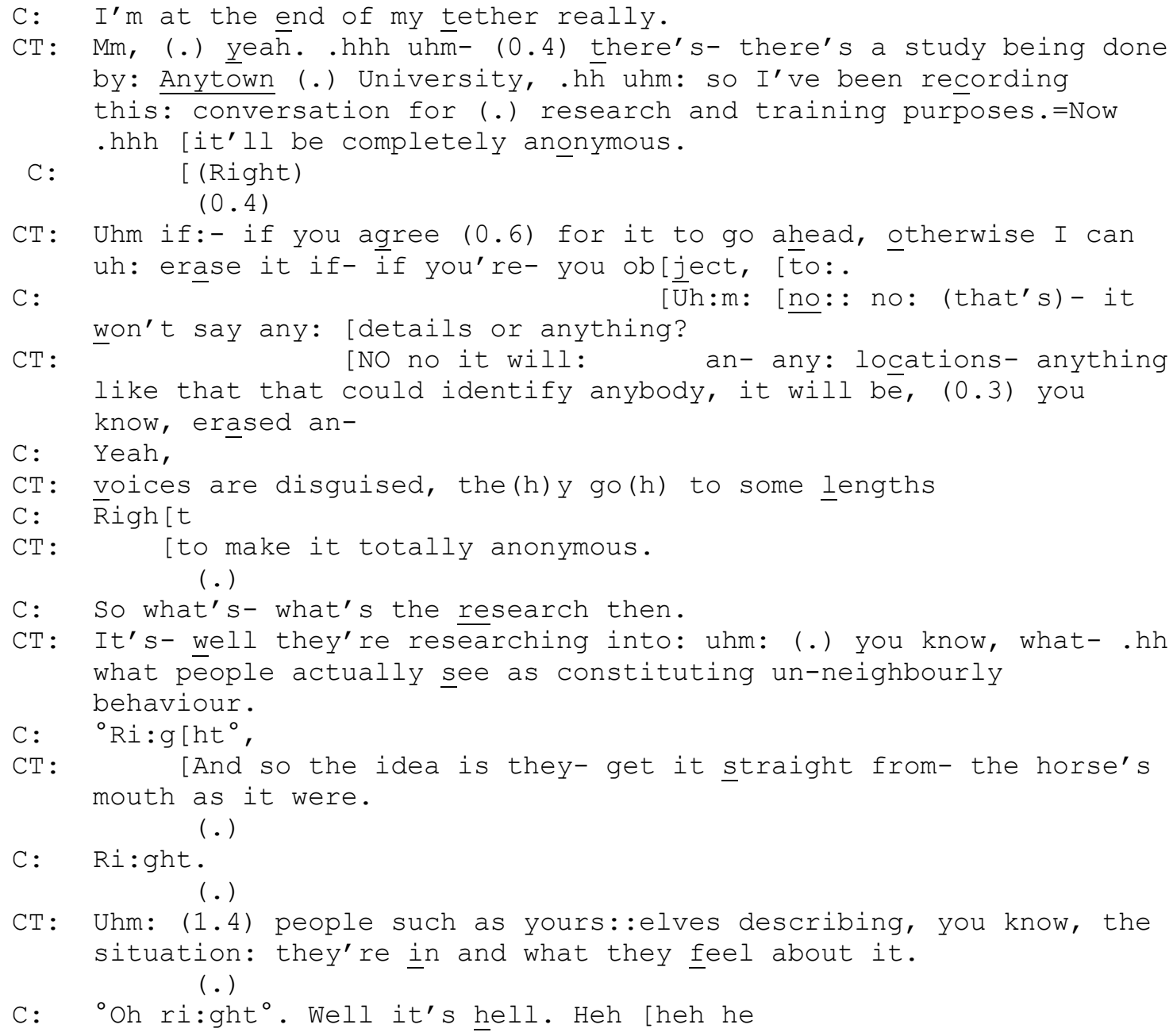

The call taker's formulation, "for (.) research and training purposes", echoes earlier extracts. Consent is solicited, firstly, by asking whether the recipient "agrees" to the recording ("if:- if you agree (0.6) for it to go ahead" [line 10]). However the 0.6 second silence acts like a "monitor space" for CT to "examine what happens or what does not happen there for its acceptance/rejection implicativeness" (Davidson, 1984: 117). Having assessed it as a possible rejection-implicative, dispreferred response, the call taker adds an incremental turn component similar to that which we saw in Extract 9 that voices potential grounds for declining consent: "if you're- you object", and offers to erase the recording (lines 10-11). Although it appears to be deployed here as a last rather than a first resort move, by offering to erase the tape the call taker may pre-empt and deflect the problems associated with the caller themselves declining consent when such an option is not explicitly on offer. In what follows 
the caller implicitly consents to the ongoing recording by rejecting the offer "Uh:m: no:: no:" (line 12), before voicing her concerns about anonymity (lines 12-13).

Extract 10 is one of a smaller number of instances where the caller expands the sequence beyond one or two pairs of turns, by asking questions about the research project and ethics-related issues (e.g., line 22). It is also one of a number of instances where, contrary to recommendations made by ethics bodies that consent is obtained prior to the commencement of the research project (e.g., GMC, 2010), the recording-party seeks consent to record at the end of the call, acknowledging that it has been recorded covertly before this point (for other examples of covert recording see Speer \& Hutchby, 2003). That expanded sequences tend to co-occur in telephone data where consent sequences are initiated at the end, rather than at the start, of calls, may not be coincidental: We have already shown that when consent is gained at the start of calls, it tends to delay and/or disrupt the institutional business of the call (e.g., the caller's problem formulation), and the progressivity of the sequence. By contrast, at the end of the call, the recipient is in a position to know what they have said and are consenting to have kept on record, and anything discussed at this point serves to delay only the call's closing. For this reason, it may be easier for the caller (and the call-taker) to raise ethical concerns at this point. We return to this issue in our discussion.

\section{(4) Extended sequences in face-to-face interaction}

So far we have examined consent-gaining sequences during routine calls to organizations, in which callers become research participants after starting out in ordinary service calls, and in telephone research interviews. In all but Extract 10, consent-gaining occurred across relatively short sequences. In this section, we consider an extended sequence involving faceto-face consent-gaining and the verbal formulation of a formal consent form from a medical setting in a social psychological research project. We include this instance to demonstrate 
what happens when the consent form is verbalized on behalf of the patient by the doctor, and to examine the way a text-based artefact impacts the format and unfolding organization of the sequence. An examination of the way the consent-form is used in the interaction allows us to further develop our understanding of the ways in which formal ethical guidelines (or consent 'in theory') get translated in consent-gaining 'practice'. An example of the consent form is shown below:

\section{Insert Figure 1 about here}

The consent form contains questions relating to patients' participation which require them circling a 'yes' or 'no' response option. Note the grammatical 'preference' of these questions. As conversation analysts have shown, questions are often, "designed for, favor, or suggest an expectation of an answer of a particular type" (Heritage, 2010: 51). Thus "yes/no or polar questions are built for particular 'agreeing' responses - that is, responses aligned to the polarity of the question and confirmatory of the proposition predicated in the question" (Heritage \& Raymond, frth; see also Raymond, 2003). We saw earlier that declarative announcements and consent-soliciting questions assume or are tilted towards a consenting response. The yes-no questions on the consent form contain propositions that are similarly grammatically tilted. However, just as the two alternative options provided by the call-taker in Extract 10 helped to pre-empt and deflect an outright refusal, the grammatical preference of the consent form questions may be rendered more open and less constraining by the option on the form to circle a yes or a no. What interests us is how these questions are translated from text to talk by the psychiatrist. Consider Extract 11, below, which comes from the end of a psychiatric assessment session. 


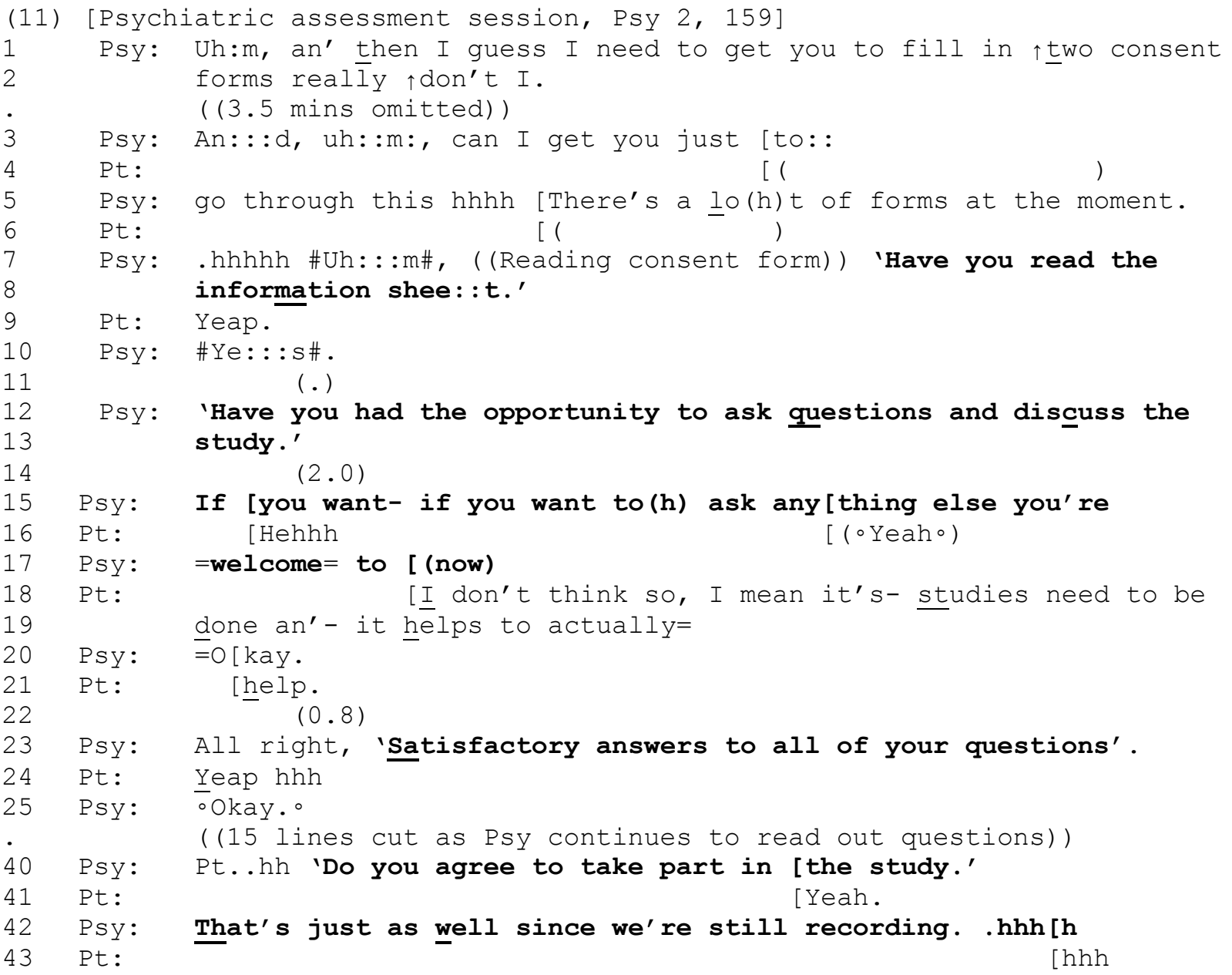

The psychiatrist takes the patient through the questions on the consent form, verbalizing them almost exactly as they appear on the form (emboldened on the transcript). Notice, however, that he delivers them without the yes-no choice format that the patient would see if they were reading the form. As a consequence, the questions are tilted strongly towards a consenting, 'yes' response (note in particular the last question - "Do you agree to take part in the study." [line 40]).

While the first question receives just such a response from the patient (line 9), the second, "Have you had the opportunity to ask questions and discuss the study", prefers a yes, but receives no response at all, and a two-second gap ensues (line 14). Such lengthy gaps tend to indicate a forthcoming dispreferred response (Pomerantz, 1984). The psychiatrist orients to this, and demonstrates what he takes to be the nature of the trouble (that the patient has not 
had an adequate opportunity to ask questions) by encouraging the patient to ask further questions (lines 15 and 17). Just as soon as the psychiatrist has begun this turn, the patient produces a laughter particle (line 16, which encourages the psychiatrist to laugh; notice the interpolated laughter in the word "to(h)" in line 15). Both parties are therefore oriented to the delicate matter that the formal procedures around consent-gaining have not gone quite as they should (Haakana, 2011).

As we know from Heritage and colleagues' work (Heritage, Robinson, Elliott, et al 2007; Heritage \& Robinson, frth) on the use by doctors of the question "Are there [some/any] other concerns you would like to talk about today?', 'any' (unlike 'some') is a word with negative polarity. So, the psychiatrist's declarative regarding "anything else" (line 15) is grammatically tilted towards a 'no-problem' response in which the patient does not have any questions, as indeed it turns out they do not at: "I don't think so" (line 18). Thus, this instance shows clearly how the relatively 'open' preference design of the questions on the consent form - the questions 'in theory' - does not get translated into equally open preferences in actual consent-gaining questions 'in practice' (see Houtkoop-Steenstra \& Antaki, 1997, on the interactional reformulation of written questions). Rather, the reality of ethics in practice is that the grammatical preferences built into consent gaining questions constrain the recipient to produce consent-giving responses.

\section{DISCUSSION}

In this paper, we have identified some interactional practices associated with the accomplishment of informed consent to social psychological research participation, across a range of institutional settings. We found, first, that consent-gaining sequences were not generally built using low entitlement, high contingency request forms (cf. Curl \& Drew, 2008), but comprised either a declarative announcement or informing (Section 1); an 
announcement-confirmation pair of turns plus a further pair that seek confirmation that consent was given (Section 2), or an announcement with the consent-solicit component built into the turn, sometimes with an opt-out clause (Section 3). These additional components were delayed, in that they were delivered at the end of the recording party's consent-gaining turns. In each case, consent-soliciting announcements were nevertheless treated by recipients as requests to record. Second, we found that, regardless of setting, participants had to 'optout' of a research process that was already underway. Consent-gaining sequences constrained opting out in two ways: (1) because research activity was already underway, it must be stopped affirmatively by participants; (2) contrary to many formal ethical guidelines, consentgaining turns, whether delivered via telephone or face-to face, were built grammatically in ways that favour continuation of the recording, making opting-out a dispreferred response (and in the case of the pre-recorded message, no option to decline consent is given). They constrained recipients to give ‘no problem' (Houtkoop-Stenstra \& Antaki, 1997), consenting responses, and to discourage expanded sequences involving 'any questions' about study participation. As the final extract showed, even where the consent form (Figure 1) contained a choice of consenting ("yes") and declining ("no") response options, its spoken translation typically omitted the 'no' option, thus re-instating a strong preference for a 'yes', consenting response. As conversation analysts have found, it is difficult to construct a yes/no question that does not convey a preference for agreement (Sacks 1987; Heritage 2010).

Like other forms of requesting (e.g., Heinemann, 2006; Toerien \& Donovan, 2007), consent-gaining turns were built for the settings they inhabit. Across the data, different states of affairs about recording were in play, from calls that 'may' be recorded to calls that were already being recorded, and from granting consent for the first time to already being a research participant and reconfirming consent. We examined cases in which people started out as callers to an organization and then, following a consent-gaining sequence, became 
social psychological research participants. These setting-specific affordances shaped consentgaining parties' orientations to their entitlement to seek consent and the contingencies involved in granting it. Although most consent-gaining turns were built with high entitlement for the institution to make the request, with low contingencies involved in granting it, we nevertheless found numerous features that lowered entitlement and raised contingencies, but across practices that, ultimately, tilted research participants towards assent.

Such findings raise questions about the extent to which participants "agreed to participate without [interactional] pressure or coercion" (GMC, 2010: 8). Although for ethical reasons we do not have recordings of research participants who declined consent (excepting an attempted decline by a researcher [Extract 3] cf. Maynard \& Schaeffer, 2002), such declines were extremely rare across our data and, in some collections, absent entirely. Generally, research participants were not concerned about their research participation. Rather, they often cut into requests before they were fully articulated, curtailing potential discussions about the research to discuss the main business of their call. And, as our analysis of Extract 3 showed, refusals can be problematic interactionally, with direct consequences for the progressivity of the interaction and researcher-participant rapport. As suggested earlier, the fact that people (including the recording parties themselves) are evidently used to being recorded without consent, for 'training' and other opaque institutional 'purposes' (Section 1), and are used to hearing somewhat idiomatic formulations thereof, may account both for the grammatical design of consent-gaining turns (the recording parties use similar 'announcement' formats to pre-recorded messages, and to each other despite working in different institutional settings), and the apparent willingness of participants to give their research participation. It is not the aim of this paper to discuss in any detail sociological debate about, say, the surveillance society (e.g., Foucault, 1977). However, it is hard to resist 
noticing the apparent ease with which, in a "recording culture" such as ours, recording parties obtain consent from research participants (see Marx, 2003).

A further factor that may account for our findings is the dispreferred nature of both requests as first pair part 'initiating' actions, and rejections or consent-declines as second pair part 'responsive' actions (Gill, Halkowski \& Roberts, 2001; Schegloff, 2007). As Gill et al show, in certain institutional settings where there is an asymmetry between parties, 'requesting' is a delicate action: "to request is to open the door to the awkward if not facethreatening prospect of being refused" (2001: 57). It follows that "in everyday interaction ... requests fall under the rubric of actions best entered into from an angle: if one does not actually ask, one can avoid being refused outright" (ibid: 57). Thus, in our consent-gaining sequences, we see how recording participants negotiate their way through these dilemmas by formulating the dispreferred action of a request without actually doing it outright (ibid.: 57, Sacks 1992, vol. 2: 413). Indeed, the fact that multiple actions can be achieved via the same grammatical form helps to account for the apparent mismatch in our data between the surface form of the consent-gaining turns built as declarative announcements and their routine projectability and treatment by recipients as requests.

By treating the process of consent-gaining as a topic for analysis, we have found that there are discrepancies between what guidelines and ethics committees specify 'in theory' about procedures for gaining consent and what actually happens 'in practice'. We do not, however, want to suggest that we have found examples of unethical or poor research. Rather, we want to make a more general point; that guidelines of all kinds are based on a misunderstanding of how interaction works, and an assumption that it is both possible and desirable to translate written scripts unproblematically, and pristinely, into spoken interaction. As Stokoe (2011; frth.) has shown, there are both gross and subtle differences between simulated and actual conversation; between guidelines-for-talk and talk itself; 
between 'talk-in-theory' and 'talk-in-practice'. Guidelines do not engage with the interactional contingencies and preference structures associated with the everyday actions of 'requesting' and 'declining' that we have highlighted; actions that may become especially problematic when there is an asymmetry of institutional roles (Gill et al., 2001),

We are not suggesting that these contingencies should or can be eliminated, or that researchers attempt to standardize ethics scripts in a bid to 'engineer out' interactional preference from consent-gaining sequences. Nor should we take our findings to mean that consent should only ever be sought in writing (as with the consent form in Figure 1), where the provision of both consenting and declining options can be strictly controlled, but where there is no provision for recipients to ask questions of researchers. As others have shown, even where a researcher has standardization as their explicit goal, it does not tend to occur in practice, where, again, the 'interactional imperative' comes into play (e.g., Gibson, 2011; Maynard et al., 2002; Maynard \& Schaeffer, 2006; Schegloff, 2002, Stokoe, frth.). We cannot stop people from talking using normative conversational procedures. However, we might seek to understand how interaction works before constructing guidelines for actions that are to be delivered interactively (Stokoe, 2011). Research interactions are not exempt from talk's everyday procedures, and are no less interactional by virtue of their status as research.

The impossibility of eliminating such structures from research interactions may tempt one to conclude that "the only safe way to avoid violating principles of professional ethics is to refrain from doing social research altogether" (Bronfenbrenner 1952: 453). However, it may be more productive simply to acknowledge that there may always be a tension between maximizing consent to participate in research and ensuring that decisions to participate or not are fully informed (Wade et al., 2009: 2025). Ultimately, ethical research practice comes from understanding the possible effects of our interactions on participants. A conversation analytic approach to research methodology permits a reflexive approach to consent-gaining 
interactions (Lomax \& Casey, 1998; Speer, 2002c), and researcher training which involves those parties who may be responsible for collecting data from recipients, discussing precisely these kinds of interactions, reflecting on what works well, what works less well, and for whom, and an awareness of the implications of delivering their consent-gaining turns in different ways.

Our data point to practices that may mitigate the appearance of interactional constraint or coercion, providing, at least on a surface level, a greater degree of choice to participants: First, consent-gaining parties may provide opportunities for participants to 'opt in' to the research process, prior to the commencement of the recording. Second, they may be encouraged to lower the entitlement and increase the contingency of their consent-gaining turns, and open up the range of possible response options available to recipients (as in Extracts 9 and 10), by formulating their consent requests in ways that acknowledge, or explicitly voice the grounds upon which participants may wish to decline their consent. Third, to maximize opportunities for fully informed consent, and minimize disruption to the institutional business and progressivity of the interaction, it may be more effective to initiate consent-gaining sequences at the end, rather than the start of a recording (as in Extract 10). This contradicts directly guidelines that consent should be gained before participation but, as we have argued, such guidelines are unlikely to have been drawn up on the basis of empirical evidence. In contrast, we have provided evidence for interventions in research methods practice, and to provide the basis for meaningful discussion about what constitutes 'fully informed consent'. Finally, BPS guidelines stipulate that psychologists should 'keep adequate records of when, how and from whom consent was obtained" (BPS, 2009: 12). As we have shown in this paper, the fact that consent-gaining sequences are built into data collection means that conversation analytic and other forms of interactionally-based research are perhaps uniquely placed to address this stipulation. Indeed, such research, perhaps more 
than any other social psychological approach, provides the analytic resources to put a commitment to reflexivity into practice. 


\section{References}

American Psychological Association (2010). Ethical principles of psychologists and code of conduct. Online document, retrieved 23 February 2012 from: http://www.apa.org/ethics/code/index.aspx

Berg, J. W., Appelbaum, P. S., Lidz, C. W., \& Parker, L. S. (2001). Informed consent: Legal theory and clinical practice. (2nd ed). New York, Oxford University Press.

British Psychological Society (2009). Code of ethics and conduct. Leicester: British Psychological Society.

Bronfenbrenner, U. (1952). Principles of professional ethics: Cornell Studies in Social Growth. American Psychologist, 7, 452-55.

Curl, T. S., \& Drew, P. (2008). Contingency and action: A comparison of two forms of requesting. Research on Language \& Social Interaction, 41/2, 129-53.

Davidson, J. A. (1984). Subsequent versions of invitations, offers, requests, and proposals dealing with potential or actual rejection. In A. J. Maxwell, J. Heritage (Eds.), Structures of social action: Studies in conversation analysis (pp. 102-28). Cambridge: Cambridge University Press.

Drew, P., Raymond, G., \& Weinberg, D. (Eds.) (2006). Talk and interaction in social research methods. London: Sage.

Dunn, L. B., \& Jeste, D. V. (2001). Enhancing informed consent for research and treatment. Neuropsychopharmacology, 24, 595-607.

Eyler, L. T. \& Jeste, D. V. (2006). Enhancing the informed consent process: A conceptual overview. Behavioral Sciences and the Law, 24, 553-68.

Flory, J. \& Emanuel, E. (2004). Interventions to improve research participants' understanding in informed consent for research: A systematic review. JAMA, 292, 1593-1601. 
Garfinkel, Harold (1967). Studies in ethnomethodology. Englewood Cliffs, N.J.: PrenticeHall.

General Medical Council (2008). Consent: Patients and doctors making decisions together. Online document, retrieved 27 February 2012 from: http://www.gmcuk.org/static/documents/content/Consent_0510.pdf

General Medical Council (2010). Good practice in research and consent to research. Online document, retrieved 27 February 2012 from: http://www.gmcuk.org/static/documents/content/Research_guidance_FINAL.pdf

Gibson, S. (2011). Milgram's obedience experiments: A rhetorical Analysis. British Journal of Social Psychology. ****, 1-19.

Gilbert, G.N., \& Mulkay, M. (1984). Opening Pandora's Box: A sociological analysis of scientists' discourse. Cambridge: Cambridge University Press.

Gill, V. T., Halkowski, T., \& Roberts, F. (2001). Accomplishing a request without making one: A single case analysis of a primary care visit. Text, 21, 55-81.

Haakana, M. (2001). Laughter as a patient's resource: Dealing with delicate aspects of medical interaction. Text, 21, 187-219.

Hammersley, M. (2003). Analytics are no substitute for methodology: A response to Speer and Hutchby. Sociology, 37, 339-52.

Heinemann, T. (2006). "'Will you or can't you?': Displaying entitlement in interrogative requests. Journal of Pragmatics, 38, 1081-1104.

Hepburn, A., \& Potter, J. (2011). Designing the recipient: Some practices that manage advice resistance in institutional settings. Social Psychology Quarterly, 74, 216-241.

Heritage, J. (2010). Questioning in medicine. In A. F. Freed \& S. Ehrlich (Eds.), "Why do you ask?": The function of questions in institutional discourse (pp. 42-68). New York, Oxford University Press. 
Heritage, J.\& Raymond, G. (frth). 'Navigating epistemic landscapes: Acquiescence, agency and resistance in responses to polar questions. In J.P. de Ruiter (Ed.), Questions: Formal, functional and interactional perspectives. Cambridge: Cambridge University Press.

Heritage, J. \& Robinson, J. D. (2011). "Some” vs “any" medical issues: Encouraging patients to reveal their unmet concerns. In C. Antaki (Ed.), Applied conversation analysis: Intervention and change in institutional talk. Palgrave Macmillan (pp. 15-31). Basingstoke: Palgrave Macmillan.

Heritage, J., Robinson, J., Elliott, M., Beckett, M., \& Wilkes, M. (2007). Reducing patients' unmet concerns in primary care: The difference one word can make. Journal of General Internal Medicine, 22, 1429-33.

Houtkoop-Steenstra, H., \& Antaki, C. (1997). Creating happy people by asking yes-no questions. Research on Language and Social Interaction, 30, 285-313.

Jefferson, G. (2004). Glossary of transcript symbols with an introduction. In G. H. Lerner, (Ed.), Conversation analysis: Studies from the first generation (pp.13-31). Amsterdam/Philadelphia: John Benjamins.

Lindström, A. (2005). Language as social action: A study of how senior citizens request assistance with practical tasks in the Swedish home help service. In A. Hakulinen and M. Selting (Eds.), Syntax and lexis in conversation: Studies on the use of linguistic resources in talk-in-interaction (pp. 209-230). Amsterdam: Benjamins.

Livingstone, A.G., Manstead, A.R., Spears, R., \& Bowen, D. (2011).The language barrier? Context, identity, and support for political goals in minority ethnolinguistic groups. British Journal of Social Psychology, 50, 747-768. 
Lomax, H., N. \& Casey, N. (1998). 'Recording social life: Reflexivity and video methodology. Sociological Research Online, 3. Online document, retrieved 27 February 2012 from: http://www.soc.surrey.ac.uk/socresonline/3/2/1.html

Marx, G.T. (2003). A tack in the shoe: Neutralizing and resisting the new surveillance. Journal of Social Issues, 59, 369-390.

Maynard, D. W.; Freese, J. \& Schaeffer, N. C. (2010). Calling for participation: Requests, blocking moves, and rational (inter)action in survey introductions. American Sociological Review, 75, 791-814.

Maynard, D. W., Houtkoop-Steenstra, H., Schaeffer, N. C. \& van der Zouwen, J. (Eds.) (2002). Standardization and tacit knowledge. Interaction and practice in the survey interview. New York: John Wiley.

Maynard, D. W., \& Schaeffer, N. C. (2002). Opening and closing the gate: The work of optimism in recruiting survey respondents. In D. W. Maynard, H. HoutkoopSteenstra, N. C. Schaeffer \& J. van der Zouwen (Eds.), Standardization and tacit knowledge. Interaction and practice in the survey interview (pp. 179-205). New York: John Wiley.

Maynard, D. W., \& N. C. Schaeffer (2006). Standardization-in-interaction: The survey interview. In P. Drew, G. Raymond, \& D. Weinberg (Eds.), Talk and interaction in social research methods (pp. 9-27). London. Sage.

Mondada, L. (2011). Ethics in Action: Ethical issues in researchers' and participants' situated practices. Keynote paper presented at the conference "Would you mind if I record this?" Ethics and methodology in discourse interaction research. New University of Lisbon, Lisbon, Portugal, August. 
Mondada, L. (2006a). La demande d'autorisation comme moment structurant dans l'enregistrement et l'analyse des interactions bilingues. Travaux neuchâtelois de linguistique, 43, 129-55.

Mondada, L. (2006b). Video recording as the reflexive preservation and configuration of phenomenal features for analysis. In H. Knoblauch, B. Schnettler, J. Raab, \& H. G. Soeffner (Eds.), Video analysis: Methodology and methods (pp. 51-68). Oxford: Peter Lang.

National Institutes of Health (2004). Guidelines for the conduct of research involving human subjects at the National Institutes of Health. Online document, retrieved 27 February 2012 from: http://ohsr.od.nih.gov/guidelines/GrayBooklet82404.pdf

Penn, C., \& Evans, M. (2009). Recommendations for communication to enhance informed consent and enrolment at multilingual research sites. African Journal of AIDS Research, 8, 285-94.

Pomerantz, A. (1984). Agreeing and disagreeing with assessments: Some features of preferred/dispreferred turn shapes. In J. M. Atkinson, \& J. Heritage (Eds.), Structures of social action: Studies in conversation analysis (pp. 57-101). Cambridge: Cambridge University Press.

Raymond, G. (2003). Grammar and social organization: Yes/no interrogatives and the structure of responding. American sociological review, 68, 939-967.

Sacks, H. (1995). Lectures on conversation, Vols. 1 \& 2. G. Jefferson (Ed.). Cambridge, MA: Blackwell.

Schegloff, E. A. (2002). Survey interviews as talk-in-interaction. In D. W. Maynard, H. Houtkoop-Steenstra, N. C. Schaeffer \& J. van der Zouwen (Eds.), Standardization and tacit knowledge. Interaction and practice in the survey interview (pp. 151-61). New York: John Wiley. 
Schegloff, E. A. (2007). Sequence organization in interaction: A primer in conversation Analysis. Cambridge: Cambridge University Press.

Speer, S.A. (2002a). "Natural” and "contrived” data: A sustainable distinction?' Discourse Studies, 4, 511-25.

Speer, S. A. (2002b). Transcending the "natural" / "contrived" distinction: A rejoinder to ten Have, Lynch and Potter. Discourse Studies, 4, 543-48.

Speer, S.A. (2002c). What can conversation analysis contribute to feminist methodology? Putting reflexivity into practice. Discourse \& Society, 13, 783-803.

Speer, S. A., \& Hutchby, I. (2003a). From ethics to analytics: Aspects of participants' orientations to the presence and relevance of recording devices. Sociology, 39, 31537.

Speer, S. A. \& Hutchby, I. (2003b). Methodology needs analytics: A rejoinder to Martyn Hammersley. Sociology, 39, 335-59.

Speer, S. A. (2012, in press). Hypothetical questions: A comparative analysis and implications for 'applied' versus 'basic' conversation analysis. Research on Language and Social Interaction, 45.

Stivers, T., Enfield, N.J., Brown, P., Englert, C., Hayashi, M., Heinemann, T., Hoyman, G., Rossano, F., de Ruiter, J.P. Yoon, K. \& Levinson, S.C. (2009). Universals and cultural variation in turn-taking in conversation. Proceedings of the National Academy of Sciences, 106(26), 10587-92.

Stokoe, E. (2009). "For the benefit of the tape": Formulating embodied conduct in designedly uni-modal recorded police-suspect interrogations. Journal of Pragmatics, 41, 18871904.

Stokoe, E. (2011). Simulated interaction and communication skills training: The 'Conversation Analytic Role-play Method'. In C. Antaki (Ed.), Applied conversation 
analysis: Changing institutional practices (pp. 119-139). Basingstoke: Palgrave Macmillan.

Stokoe, E. (forthcoming). The (in)authenticity of simulated talk: Comparing role-played and 'real' conversation. Manuscript submitted.

Tanis, M., \& Beukeboom, C.J. (2011). Organizational identification and the communication of identity: Effects of message characteristics on cognitive and affective identification. British Journal of Social Psychology, 50 (4), 784-791.

Terasaki, A. K. (2004). Pre-announcement sequences in conversation. In G. H. Lerner (Ed.), Conversation analysis: Studies from the first generation (pp. 171-223). Amsterdam/Philadelphia: John Benjamins.

Toerien, M. \& Donovan, J. (2007). "Would you like to be randomised today?" "Randomisation request" sequences in recruitment to a cancer trial. Paper presented at the International Meeting on Conversation Analysis and Clinical Encounters, July 1618, University of Exeter, UK.

Wade, J., Donovan J. L., Lane J. A., Neal, D. E., \& Hamdy, F. C. (2009). "It's not just what you say, it's also how you say it: Opening the "black box" of informed consent appointments in randomised controlled trials. Social Science \& Medicine, 68, 201828.

Woodsong, C. \& Karim, Q. A. (2005). A model designed to enhance informed consent: Experiences from the HIV prevention trials network. American Journal of Public Health, 95, 412-19. 


\section{Figure 1}

\section{CONSENT FORM}

[1 for patient; 1 for researcher; 1 to be kept with hospital notes]

Title of Project: Transsexual Identities in the Gender Identity Clinic

Name of Researchers: Dr Susan Speer and Professor Richard Green

(The patient/volunteer should complete the whole of this sheet him/herself)

$\begin{array}{ll}\text { Have you read the Information Sheet? } & \text { Yes No }\end{array}$

Have you had the opportunity to ask questions and discuss the study? Yes No

Have you received satisfactory answers to all of your questions? $\quad$ Yes No

Have you received enough information about the study? $\quad$ Yes No

Whom have you spoken to? (write name)

Do you understand that you are free to withdraw from the study, at any time, without having to give a reason, and without affecting

the quality of your present or future medical care? Yes No

$\begin{array}{ll}\text { Do you agree to take part in this study? } & \text { Yes }\end{array}$

I understand that the local Ethics Committee may review this form as part of a monitoring process.

NAME IN BLOCK LETTERS:

Signature: Date:

SIGNATURE OF PERSON OBTAINING CONSENT

Signature:

Date: 